\title{
HUBUNGAN ANTARA KESEPIAN DAN KECENDERUNGAN NARSISISTIK PADA PENGGUNA JEJARING SOSIAL MEDIA INSTAGRAM
}

\author{
Kembaren Dianelia R. Sembiring \\ Fakultas Psikologi Universitas Kristen Satya Wacana \\ J1. Diponegoro 52-60 Salatiga \\ dianeliakembaren@gmail.com
}

\begin{abstract}
This study aims to investigate the relationship between loneliness and narcissistic tendencies on social network Instagram users. The population in this study is the users of social network Instagram for at least 6 months, aged 18-24 years, has a minimum of 90 photos on their instagram account, actively access instagram account for once until twice a day. Snowball sampling is used in this study, with the participation of 65 participants. Measurement instrument used in this study were UCLA Loneliness Scale Version 3 and the Narcissistic Personality Inventory 40 Items. Pearson's Product Moment is used to test the correlation between loneliness and narcissistic tendency. The results of this study showed that there was no relationship between loneliness and narcissistic tendency among social network Instagram users $(r=-0.080, p=.264)$.
\end{abstract}

Keywords: loneliness; narcissistic tendency; social network; instagram

\begin{abstract}
Abstrak
Penelitian ini bertujuan untuk mengetahui hubungan kesepian dengan kecenderungan narsisistik pada pengguna jejaring sosial instagram. Populasi dalam penelitian ini adalah pengguna jejaring sosial instagram yang telah aktif minimal selama 6 bulan, berusia 18-24 tahun, memiliki jumlah foto dalam akun instagram pribadi minimal 90 foto, aktif dalam mengakses akun instagram dengan rata-rata akses 1-2 hari sekali. Teknik sampling yang digunakan dalam penelitian ini adalah snowball sampling dengan partisipan sebanyak 65 partisipan. Alat ukur yang digunakan dalam penelitian ini mengacu pada UCLA Loneliness Scale Version 3 dan Narcissistic Personality Inventory 40 Item. Pearson's Product Moment digunakan untuk menghitung korelasi antara kesepian dan kecenderungan narsisistik. Hasil dari penelitian menunjukkan bahwa tidak ada hubungan antara kesepian dengan kecenderungan narsisistik pada pengguna jejaring sosial media instagram $(r=-0,080 ; p=0,264)$.
\end{abstract}

Kata kunci: kesepian; kecenderungan narsisistik; jejaring sosial; instagram

\section{PENDAHULUAN}

Dewasa ini, teknologi digital telah berkembang begitu pesat, bukan hanya penemuan-penemuan hardware baru namun juga perkembangan software yang dibuat untuk membantu aktivitas kerja hingga hiburan bagi manusia. Software atau perangkat lunak yang banyak dikembangkan saat ini salah satunya adalah berupa aplikasi berbasis gawai (gadget). Aplikasi yang menggunakan jaringan internet sebagai basis utamanya ini dimanfaatkan oleh berbagai pihak dengan rentang usia yang beragam. Fungsi dan manfaat yang ditawarkan oleh aplikasi-aplikasi tersebut juga beragam, seperti mempermudah komunikasi, pencarian informasi, berbelanja dan berjualan, mencari hiburan. Salah satu aplikasi yang banyak digunakan adalah aplikasi yang berfungsi komunikasi dan membangun jaringan, yaitu aplikasi media sosial.

Pew Research Center menemukan bahwa sebanyak $91 \%$ dari pemilik smartphone usia 18-29 tahun menggunakan jejaring sosial di smartphone mereka setidaknya 
sekali selama rentang waktu studi berjalan, dibandingkan dengan 55\% dari mereka yang berumur 50 tahun ke atas (Smith, 2015). Menurut survey yang dilakukan Marketeers (2013) hampir 70\% pengguna internet remaja menghabiskan lebih dari tiga jam sehari menggunakan internet. Tiga hal utama yang dilakukan warganet (masyarakat pengguna internet) adalah mengakses media sosial (94\%), mencari informasi (64\%), dan membuka email $(60,2 \%)$ dan menurut survei yang dilakukan oleh Pew Internet \& American Life Project menyatakan, 54\% pengguna internet punya kebiasaan mengunggah potret dirinya ke jejaring sosial yang dimiliki (Widiyani dalam Kompas 24 Agustus, 2013). Aplikasi yang dimaksud atau disebut dengan jejaring sosial media adalah blog, tumblr, my space, facebook, twitter, path, snapchat, friendster, dan instagram.

Salah satu layanan jejaring sosial media yang lebih memfokuskan penggunanya untuk mengambil dan mengunggah foto adalah instagram. Namun tidak hanya untuk mengunggah foto, instagram juga memungkinkan penggunanya untuk menggunakan filter digital agar foto terlihat lebih menarik, menggunakan fitur share location guna memberikan informasi kepada followers (pengikutnya) mengenai lokasi foto tersebut diambil dan memungkinkan penggunanya mengunggah video berdurasi 60 detik yang bisa dilihat langsung oleh para followers (pengikutnya). Jika foto atau video menarik menurut pengguna yang menjadi follower, pengguna instagram lainnya dapat memberikan komentar dan memberi tanda suka (like) kepada foto atau video tersebut dan akan muncul pada fitur pencarian pengguna lain sehingga foto atau video tersebut tersebar semakin luas dan followers menjadi bertambah. Instagram sendiri memiliki 400 juta pengguna aktif bulanan, rata-rata pengguna instagram menghasilkan 150 juta foto per bulan dan 800 juta foto serta video dipublikasikan setiap hari (Parikesit, 2016).

Perusahaan instagram mengungkapkan sejumlah fakta menarik mengenai aktivitas pengguna instagram di Indonesia. Sebanyak $59 \%$ pengguna instagram berusia 18-24 tahun, 30\% berusia 25-34 tahun, dan $11 \%$ berusia 34-55 tahun (Parikesit, 2016). Usia merupakan salah satu penentu yang kuat dari frekuensi dan kualitas penggunaan jejaring sosial media. Grant (dalam Mazman \& Usluel, 2011) mengatakan bahwa jejaring sosial media sebagian besar digunakan oleh remaja dan dewasa awal sebagai penghubung kepribadian mereka untuk ditunjukkan kepada teman-teman mereka dan dunia mengenai siapa diri mereka, apa yang mereka pedulikan dan dengan siapa mereka memiliki pemikiran yang sama. Hal ini membuktikan bahwa jejaring sosial instagram dapat menarik minat pengguna jejaring sosial media.

Para pengguna jejaring sosial media melihat bahwa dengan adanya fungsi instagram yang dapat menjadi media untuk berbagi foto dan video membuat instagram semakin lekat dengan kehidupan para penggunanya. Hal ini membuat pengguna instagram merasa harus membagi setiap aspek yang berkaitan dengan kehidupan individu tersebut termasuk pemikiran, perasaan yang sedang dirasakan, setiap pengalaman yang baik atau buruk, bendabenda yang dimiliki, tempat yang sedang dikunjungi, makanan atau minuman yang dikonsumsi bahkan pakaian yang sedang dikenakan ke dalam jejaring sosial instagramnya. Berdasarkan penelitian yang dilakukan $\mathrm{Hu}, \quad$ Manikonda \& Kambhampati (2014) terdapat delapan kategori foto favorit di instagram yaitu kategori foto selfie, teman, makanan, gawai, captioned photo (gambar dengan kata-kata), hewan, aktivitas, dan fashion. Beberapa individu sering menggunakan jejaring sosial media untuk memperlihatkan versi ideal dari diri atau 
kehidupan mereka, cenderung lebih menekankan pada hal-hal yang positif dan meminimalisir yang negatif. Ini bukan hanya membuat mereka "menipu" orang lain, tetapi juga "menipu" diri mereka sendiri (Austin, 2013). Hal ini juga didukung oleh Puspitasari (2016) yang menyatakan hal-hal yang ditampilkan pada lingkungan adalah sisi baik individu.

Pada dasarnya, kecenderungan individu untuk memperlihatkan versi ideal kehidupan melalui fotografi maupun video berhubungan dengan adanya kecenderungan narsisistik pada diri individu tersebut. Narsisistik adalah sifat kepribadian yang merefleksikan waham kebesaran (grandiose) dan konsep diri yang melambung. Secara khusus, perilaku narsisistik berhubungan dengan pandangan diri yang positif dan meninggi pada sifatsifat tertentu seperti inteligensi, kekuatan, dan daya tarik diri (Buffardi \& Campbel, 2008). Raskin dan Terry (dalam Winardi \& Permana, 2015) menjelaskan narsisistik berkembang dalam lingkungan yang memberikan penghargaan karena adanya perhatian positif dari individu lain kepada individu yang narsisistik. Adi \& Yudiati (2009) menambahkan berdasarkan penelitian yang telah dilakukan individu dikatakan cenderung narsisistik ketika seseorang tersebut cenderung pamer akan kelebihan-kelebihannya dengan menceritakan hal-hal mengenai dirinya sendiri pada akunnya dan enggan berbagi tips-tips bahkan ketika orang lain meminta bantuan. Perempuan yang narsisistik cenderung lebih mengarah kepada masalah body image agar merasa unggul dan mendapat kekaguman dari orang lain. Mereka memamerkan keindahan fisik dan seksualitas untuk mendapatkan kekaguman dari laki-laki. Sedangkan laki-laki yang narsisistik biasanya lebih berfokus pada inteligensi, kekuatan (power), agresi, uang dan status sosial untuk memenuhi rasa keunggulan dari citra diri mereka yang salah (Goodman \& Leff, 2012).
Seorang remaja memamerkan foto-foto kekayaan yang dimilikinya seperti tidurtiduran dengan tumpukan uang ribuan dolar, membuang uang sebanyak $\$ 4000$, memamerkan tas-tas branded dengan status "orang bekerja sampai siang, namun hanya mendapatkan separuh dari harga tas ini" (Noname, 2013). Bahkan demi mendapatkan foto-foto yang dapat dipamerkan dalam akun sosial media individu tidak ragu untuk melakukan hal ekstrim hingga merenggut nyawa. Seperti berita yang dimuat dalam Liputan 6 (Yulee, 2015) seorang mahasiswa terjatuh dalam kawah sedalam 100-200 meter dan ditemukan meninggal dunia pada saat melakukan selfie di atas Puncak Garuda Gunung Merapi. Selain itu remaja perempuan asal Italia kehilangan nyawanya saat ingin berfoto selfie dari tebing di pinggir pantai laut Tarato. Remaja tersebut diketahui tengah mencari lokasi yang bagus agar ia mendapatkan hasil yang bagus saat berfoto selfie, namun terjatuh dari ketinggian 18 meter dan meninggal dunia.

Hidayati (2010) mengatakan bahwa motivasi individu menggunakan media sosial adalah untuk menjalin komunikasi dengan orang lain dan akan merasakan kepuasan ketika melakukannya secara terus menerus. Rinjani \& Firmanto (2013) menambahkan individu yang mengunggah foto dan video dapat memenuhi kebutuhan untuk menjalin hubungan dengan individu lain, karena dengan media sosial individu dapat berkoneksi dengan jejaring sosial yang luas dan dapat membuat individu tersebut semakin dikenal oleh individu lain. Hal itu didukung dengan penelitian yang telah dilakukan oleh Aryaguna (dalam Puspitasari, 2016) bahwa adanya like dan komentar yang diberikan oleh pengguna instagram yang lain dapat menimbulkan rasa mendapatkan dukungan emosional dan psikologis sehingga individu terdorong untuk semakin mengunggah foto dan video dalam akun instagramnya. Bergman

(2011) 
mengatakan bahwa individu percaya bahwa individu lain yang berada di sosial media tertarik dengan kehidupan mereka sehingga hal tersebut menjadi suatu dorongan untuk mengunggah foto-foto mereka sendiri yang mengarah pada kecenderungan narsisistik di media sosial.

Terdapat penelitian yang menemukan bahwa komunikasi secara online memiliki potensi untuk meningkatkan dukungan sosial dan harga diri sekaligus mengurangi kesepian dan depresi (Shaw \& Gant, 2002). Hal ini sependapat dengan Sundar (dalam Pittman \& Reich, 2016) bahwa instagram memberikan penurunan yang signifikan terhadap kesepian yang dialami oleh penggunanya sendiri. Dalam instagram individu dapat mengunggah foto atau video sesuai dengan yang diinginkan dengan harapan agar orang lain memberikan tanda suka (like) atau komentar yang ada di bawah foto atau video, ini menunjukkan bahwa keberadaan individu tersebut diterima dalam lingkungan sosial (Puspitasari, 2016), sehingga membuat indvidu mengunggah terus menerus foto atau video ke instagram.

Hasil riset yang dilakukan oleh Sadikides dkk. (2004) menyatakan bahwa faktor yang mempengaruhi narsisistik adalah kesepian. Penelitian yang dilakukan oleh Adi \& Yudiati (2009) juga menemukan bahwa kesepian menjadi salah satu faktor dari kecenderungan narsisistik. Kim, LaRose \& Peng (2009) mengatakan individu kesepian memiliki tingkat kecenderungan yang tinggi untuk melakukan interaksi sosial melalui media sosial. Hal ini juga didukung oleh Bian \& Leung (2015) yang mengungkap bahwa semakin tinggi tingkat kesepian maka semakin tinggi kecenderungan seseorang akan ketagihan pada penggunaan smartphone, termasuk pada penggunaan aplikasi media sosial. Kim, LaRose \& Peng (2009) menjelaskan lebih lanjut individu yang kesepian merasa mereka dapat berinteraksi dan mengekspresikan diri lebih baik pada sosial media daripada di dunia nyata, hal ini yang membuat kesepian dapat meningkatkan interaksi sosial individu di media sosial. Ryan \& Xenos (2011) menambahkan bahwa individu yang kesepian cenderung menghabiskan lebih banyak waktu di sosial media (facebook).

Menurut Peplau \& Perlman (dalam Oguz \& Cakir, 2014) kesepian adalah perasaan emosi yang dirasakan ketika individu beranggapan bahwa kehidupan sosialnya lebih kecil daripada apa yang mereka inginkan, atau ketika individu merasa tidak puas dengan kehidupan sosialnya. Hal ini serupa dengan Russell (1996) yang mengatakan individu kesepian karena individu tidak mendapatkan kehidupan sosial yang diinginkan pada kehidupan di lingkungannya. Kesepian juga dapat menyerang individu setiap saat, tanpa memilih tempat atau keadaan. Individu dalam sebuah keramaian dapat mengalami kesepian karena merasa terasing, individu tersebut merasa tidak terpenuhi kebutuhan sosialnya meskipun dikelilingi orang banyak (Graham, 1995). Russell (1996) menyatakan karakteristik individu yang kesepian adalah akan cepat marah, lebih suka menyendiri, dan tidak bisa bergaul dengan orang lain di lingkungan sekitarnya atau kaku. Menurut sebuah survei yang dilakukan oleh Mental Health Foundation, $48 \%$ remaja di Inggris percaya bahwa orang Inggris merasa kesepian seiring dengan berjalannya waktu, $45 \%$ melaporkan merasa kesepian setidaknya beberapa kali dalam satu waktu dan $42 \%$ merasa tertekan karena sendirian (Griffin, 2010).

Adapun hasil penelitian yang dilakukan oleh Erlina (2015) menemukan bahwa adanya hubungan negatif antara kesepian dengan narsisme, sehingga semakin kesepian pengguna path maka semakin rendah kecenderungannya untuk berperilaku narsisistik. Kemudian 
penelitian yang dilakukan Ryan \& Xenos (2011) mengenai hubungan antara big five, rasa malu, narsisistik, kesepian dan penggunaan facebook menemukan bahwa individu yang menggunakan facebook cenderung lebih membuka diri dan narsisistik namun kurang berhati-hati dan mengalami kesepian dalam hubungan sosial dibanding dengan bukan pengguna facebook.

Berdasarkan penjelasan fenomena di atas dan pro kontra yang terjadi pada penelitian sebelumnya, maka peneliti tertarik untuk mengetahui ada tidaknya hubungan antara kesepian dengan kecenderungan narsisistik pada pengguna jejaring media sosial instagram.

\section{METODE}

Kriteria subjek dalam penelitian ini adalah dewasa awal, berusia 18-24 tahun, memiliki akun instagram pribadi dan telah bergabung selama 6 bulan atau lebih, memiliki jumlah foto dalam akun instagram pribadi 90 foto atau lebih, aktif dalam mengakses akun instagram (mengupload foto atau video, memberikan tanda suka, memberikan komentar, memeriksa pemberitahuan, mengakses halaman depan atau explore) dengan rata-rata akses 1-2 hari sekali (Rahmanita, 2014). Teknik penentuan sampel yang digunakan adalah snowball sampling yaitu, sampling penentuan sampel yang mula-mula jumlahnya kecil, kemudian membesar (Sugiyono, 2012). Selanjutnya diperoleh sampel sebanyak 65 orang.

Alat ukur dalam penelitian ini terdiri dari 2 skala, yaitu: Skala UCLA Loneliness version 3 yang dikembangkan oleh Russell (1996), terdiri dari 20 item, kemudian teknik pengukuran untuk menguji reliabilitas menggunakan teknik koefisien Alpha Cronbach. Hasil koefisien Alpha pada skala UCLA Loneliness item sebesar 0,807. Hal ini berarti skala UCLA Loneliness reliabel.
Skala NPI-40 item dikembangkan oleh Raskin \& Terry (dalam Winardi \& Permana, 2015). Skala ini terdiri dari 40 item yang masing-masing item memiliki 2 pernyataan yaitu pernyataan respon narsisistik dan respon tidak narsisistik. Teknik pengukuran untuk menguji reliabilitas menggunakan teknik koefisien Alpha Cronbach. Hasil koefisien Alpha pada skala NPI-40 item sebesar 0,713. Hal ini berarti skala NPI-40 item reliabel.

\section{HASIL DAN PEMBAHASAN}

Berdasarkan analisis data penelitian mengenai hubungan kesepian dengan kecenderungan narsisistik pada pengguna jejaring media sosial instagram, didapatkan hasil uji perhitungan korelasi bahwa kedua variabel memiliki korelasi negatif yang tidak signifikan $(r=-0,080 ; p$ $=0,264)$ yang berarti kedua variabel, yaitu kesepian dengan kecenderungan narsisistik, tidak memiliki hubungan. Hal ini berarti $\mathrm{H}_{1}$ ditolak dan $\mathrm{H}_{0}$ diterima. Hasil ini menunjukkan bahwa tinggi rendahnya kesepian pengguna jejaring media sosial instagram tidak berhubungan dengan tinggi atau rendahnya kecenderungan narsisistik. Hasil penelitian ini tidak sejalan dengan hasil penelitian Sundar (dalam Pittman \& Reich, 2016) yang menyatakan instagram memberikan penurunan yang signifikan terhadap kesepian yang dialami oleh penggunanya sendiri.

Dalam penelitian ini ditemukan bahwa subjek penelitian mengalami kesepian yang rendah yaitu sebanyak 31 subjek $(47,69 \%)$. Namun, rendahnya tingkat kesepian subjek tidak berhubungan dengan kecenderungan narsisistik, di mana hasil analisis deskriptif menunjukkan kecenderungan narsisistik subjek penelitian yang tergolong ke dalam kategorisasi rendah yaitu sebanyak 29 subjek $(44,62 \%)$, sedangkan yang tergolong kategori tinggi sebanyak 25 subjek $(38,46 \%)$. Temuan dalam penelitian 
ini menunjukkan bahwa terdapat faktor lain yang mempengaruhi kecenderungan narsisistik. Raskin \& Terry (dalam Winardi \& Permana, 2015) mengatakan narsisistik berkembang dalam lingkungan yang memberikan penghargaan karena adanya perhatian positif dari individu lain kepada individu yang narsisistik. Berdasarkan penelitian yang telah dilakukan Adi \& Yudiati (2009) individu dikatakan cenderung narsisistik ketika seseorang tersebut cenderung pamer akan kelebihan-kelebihannya dengan menampilkan hal-hal mengenai diri nya sendiri pada akunnya. Hasil penelitian Campbell (2000) mengatakan bahwa kecenderungan narsisistik justru sebagai alat untuk menutupi kelemahan dan kekurangannya, yakni harga diri yang rendah.

Adapun faktor-faktor lain yang memengaruhi kecenderungan narsisistik di media sosial berdasarkan hasil penelitian Sedikides, Gregg, Rudich, Kumashiro, \& Rusbult (2004) adalah self-esteem. Seseorang yang mengalami ketidakstabilan dalam faktor self-esteem akan sangat bergantung pada interaksi sosial. Faktor lain yang mempengaruhi kecenderungan narsisistik adalah depresi di mana orang dengan kondisi depresi berpikiran negatif akan diri sendiri, lingkungan dan masa depan, juga mengalami rasa bersalah dan menarik diri dalam manjalani kehidupannya. Di samping itu, subjective well-being juga merupakan faktor yang mempengaruhi kecenderungan narsisistik di mana seseorang merasakan kebahagiaan hanya sebatas pada suatu hal.

\section{SIMPULAN}

Mengacu pada hasil penelitian yang didapatkan, maka kesimpulan dari penelitian ini adalah tidak terdapat hubungan antara kesepian dengan kecenderungan narsisistik pada pengguna jejaring sosial media instagram $(r=-0,080$; $p=0,264)$.

\section{DAFTAR PUSTAKA}

Adi, P. S. \& Yudiati, M. E. A. (2009). Harga diri dan kecenderungan narsisme pada pengguna Friendster (Skripsi tidak dipublikasikan). Fakultas Psikologi Universitas Katolik Soegijapranata, Semarang.

Austin, M. W. (2013). Self-deception and social media. Diunduh dari http://www.psychologytoday.com/bl og/ethics-everyone/201305/selfdeception-and-social-media.

Bergman, S. M., Fearrington, Matthew, E., Devenport, Shaun W., \& Bergman, J. Z. (2011). Millennials, narcissim, and social networking: What narcissists do on social networking sites and why. Personality and Individual Differences, 50, 706-711.

Bian, M, \& Leung, L. (2015). Linking loneliness, shyness, smartphone addiction symptoms, and patterns of smartphone use to social capital. Social Science Computer Review, 33, 61-79.

Buffardi. L. E. \& Campbell, W. K. (2008). Narcissism and social networking web sites. Personality and Social Psychology Bulletin, 34, 1303-1310.

Campbell, W. K. (2000). Narcissism and comparative self-enhancement strategies. Journal of Research in Personality, 34, 235-243.

Erlina (2015). Hubungan antara kesepian dengan narsisme pada pengguna path (Skripsi tidak dipublikasikan). Fakultas Psikologi Universitas Muhamadiyah Malang.

Graham, B. (1995). Kesepian: Bagaimana cara menyembuhkannya? Sukses dan Prestasi: Rahasia Pembaharuan Diri, 4, 11-17. 
Goodman, C. L \& Leff, B. (2012). The everythings. Guide to narcississtic personality disorder. Massachusetts: Adam Media.

Griffin, J. (2010). The lonely society? London: Mental Health Foundation.

Hidayati, A. (2010). Motivasi dan kepuasan menggunakan jejaring sosial facebook (Skripsi tidak dipublikasikan). Jurusan Ilmu Komunikasi Fakultas Ilmu Sosial dan Politik Universitas Sebelas Maret, Surakarta.

Hu, Y., Manikonda, L., \& Kambhampati, S. (2014). What we instagram: A first analysis of instagram photo content and user types. In Proceedings of the 8th International Conference on Weblogs and Social Media, ICWSM 2014, 595-598.

Kim, J., LaRose, R., \& Peng, W. (2009). Therelationship between internet use and psychological well-being. Rapid Communication, 12, 451-452.

Marketeers. (2013). Markplus insight: Pengguna internet Indonesia 74 juta di tahun 2013. Diunduh dari http://nasional.republika.co.id/ber ita/nasional/hukum/16/02/22/trendtek/ internet/13/10/28/mvdcxp-surveipengguna-internet-di-indonesiamencapai-74-juta-orang

Mazman, S. G. \& Usluel, Y. K. (2011). Gender differences in using social networks. TOJET: The Turkish Online Journal of Educational Technology, 10, 133-137.

Noname. (2013). Lagi-lagi remaja pamer kekayaan di instagram dan bikin heboh dunia maya. Vemale, 7 Mei 2013. Diunduh tanggal 24 Agustus 2016

http://www.vemale.com/ragam/2192 4-lagi-lagi-remaja-pamer-kekayaandi-instagram-dan-bikin-heboh-duniamaya.html.

Oguz, E \& Cakir, O. (2014). Relationship between the levels of loneliness and internet addiction. Anthropologist, 18, 183-189.

Parikesit, A. G. (2016). Fakta menarik pengguna instagram Indonesia. CNN Indonesia 18 Januari 2016. Diunduh tanggal 24 Agustus 2016 dari: http://www.cnnindonesia.com /teknologi/20160118150454-188105071/fakta-menarik-penggunainstagram-di-indonesia/

Pittman \& Reich. (2016). Social media and loneliness: Why an Instagram picture may be worth more than a thousand Twitter words. Computers in Human Behavior, 62, 155-167. doi : http://dx.doi.org/10.1016/j.chb.2016. 03.084 .

Puspitasari (2016). Kebutuhan yang mendorong remaja untuk memposting foto atau video pribadi dalam instagram. Jurnal Psikologi Terapan , 5, 75-84.

Rahmanita, U. (2014). Perbedaan kecenderungan narsisistik antara laki-laki dan perempuan pengguna jejaring sosial Instagram (Skripsi tidak dipublikasikan). Fakultas Psikologi Universitas Brawijaya, Malang.

Russell, D. W. (1996). UCLA Loneliness Scale (Version 3): Reliability, validity, and factor structure. Lawrence Erlbaum Associates, 66, 20-40.

Ryan, T. \& Xenos, S. (2011). Who uses Facebook? An investigation into the relationship between the Big Five, shyness, narcissism, loneliness, and 
Facebook usage. Computers in Human Behavior, 27(5), 1658-1664.

Sadikides, C., Gregg, A. P., Rudich, E. A., Kumashiro, M., \& Rusbult, C. (2004). Are normal narcissists psychologically healthy. Self-esteem matters. Journal of Personality and Social Psychology, 87, 400 - 416.

Shaw, L. H., \& Gant, L. M. (2002). In defense of the Internet: The relationship between internet communication and depression, loneliness, self-esteem, and perceived social support. CyberPsychology \& Behavior, 5, 157-171.

Smith, A. (2015). Pew research center: the smartphone difference. Diunduh dari http://www.pewinternet.org/2015/04/ 01/us-smartphone-use-in-2015/

Sugiyono. (2012). Metode penelitian kuantitatif kualitatif dan $R \& D$. Bandung: Alfabeta.
Widiyani, R. (2013). Apa kata psikolog soal foto narsis di jejaring sosial. Kompas 12 December 2013. Diunduh tangga 24 Agustus 2016: http://health.kompas.com/read/2013/ 12/18/1151301/Apa.Kata.Psikolog.s oal.Foto.Narsis.di.Jejaring.Sosial.

Winardi, R. D. \& Permana, Y. (2015). Pengaruh skeptisme profesional dan narsisme klien terhadap penilaian auditor eksternal atas resiko kecurangan. Skripsi. Fakultas Psikologi Universitas Gadjah Mada Yogyakarta.

Yulee, Y. (2015). Tragis 6 kisah selfie berujung maut. Liputan 618 mei 2015. Diunduh tanggal 24 Agustus 2016 dari: http://citizen6.liputan6.com/read/223 4137/tragis-6-kisah-selfie-berujungmaut. 